\title{
CARACTERÍSTICAS DEL TURISMO DE LUNA DE MIEL: APROXIMACIÓN AL TURISTA CHINO
}

\author{
Cristina Aragonés Jericó \\ Universidad de Valencia \\ Mengting $W u$ \\ Florida Universitaria
}

\section{RESUMEN}

En el presente trabajo, enmarcado en el turismo alternativo, se estudia el turismo de luna de miel, la elección del destino turístico y los turistas chinos en el mercado internacional. Se concluye que el turismo de luna de miel es un tipo de turismo alternativo específico con 5 características distintivas: larga duración y planificación, temporada propia, público objetivo joven, necesidades particulares y toma de decisión compartida. La investigación muestra que para los turistas chinos este tipo de turismo presenta sus propias peculiaridades.

Palabras clave: Turismo alternativo, luna de miel, atributos del destino, turistas chinos.

\section{Characteristics of honeymoon tourism: Chinese tourist approach}

\begin{abstract}
Within alternative tourism framework, the aim of this paper is to research tourism honeymoon, to choose the destination and to study Chinese tourists on the international market. It is concluded that tourism honeymoon is a specific type of alternative tourism with five distinctive features: long-term and planning, own season, young target, particular needs and shared decision-making. The result of the research shows that Chinese tourists have its own peculiarities for this type of tourism.
\end{abstract}

Keywords: Alternative tourism, honeymoon, destination attributes, Chinese tourists.

Recibido: 5 de noviembre de 2015

Devuelto para su revisión: 3 de noviembre de 2016

Aceptado: 20 de febrero de 2017

Facultad de Economía. Universidad de Valencia. Avda Tarongers, s/n. 46022 VALENCIA (España). E-mail: cristina.aragones@uv.es 


\section{INTRODUCCIÓN}

A lo largo de la historia, determinados destinos, categorías de productos y productos turísticos han entrado en una fase de declive, mientras que otros han experimentado incrementos de demanda. Por ello, las empresas y los destinos deben renovar y modernizar su oferta, adaptándola a las nuevas exigencias de la demanda (Aragonés, 2013).

Así, se observa un relativo estancamiento del turismo tradicional centrado en el modelo turístico de sol y playa y asociado a un turismo de masas, con más impactos negativos y señales de agotamiento en el ámbito nacional (Ponce, 2004; Cooper y Hall, 2008). De ahí la proyección del turismo alternativo centrado en otros tipos de turismo; como el turismo de interior o rural (Albaladejo y Díaz, 2003), el turismo de salud y cultural (García y Artal, 2002; García, Artal y Ramos, 2002a; García, Artal y Ramos, 2002b; Ruíz, Sánchez y Artal, 2003), el turismo urbano (Troitiño, 2002; Bacci, 2007) o el turismo de eventos deportivos (Getz, 2005, 2008; Aragonés, 2013); que se caracterizan por disponer de algún aspecto que por si mismo despierta el interés de un número significativo de personas, logrando que se trasladen al destino donde se encuentran para disfrutarlos. Por tanto, estos turismos dependen, más que otros, de las motivaciones de los turistas (Luque, 2003).

En este marco, ante la relevancia del turismo alternativo en la actualidad, la presente investigación abordará en profundidad un tipo concreto de turismo alternativo: el turismo de luna de miel. La investigación académica sobre turismo de luna de miel es escasa a nivel internacional e inexistente a nivel nacional. Sin embargo, contribuye significativamente a la economía turística debido a que este tipo de turistas gastan mucho más que otros en sus viajes (Winchester, Winchester y Alvey, 2011). Por lo que, como afirman Kim y Agrusa (2005) este tipo de turismo es demasiado importante para ser ignorado. De hecho, está siendo cada vez más valorado por las administraciones y las empresas turísticas en diferentes zonas de España. Podemos citar algunos ejemplos: (i) la Secretaría de Turismo del Partido Andalucista promocionó Andalucía en 2014 como destino de bodas, con el eslogan Wed Andalusia (cásate con Andalucía) que lanzó a las agencias de viajes y turoperadores de Europa (Partido Andalucista, 2014). (ii) Turismo de Canarias lanzó en el marco de FEBODA 2014 una plataforma de turismo de bodas, luna de miel y viajes románticos, que está destinada a captar a los novios europeos que desean celebrar su boda en un entorno romántico (www.canariasdiario.com). (iii) Las cadenas hoteleras españolas han prestado mucha atención a los viajes de luna de miel, existiendo entre 140-150 hoteles sólo para adultos en España (habiendo unos 600 hoteles de este tipo en todo el mundo) (ABC.es, 2014; Vallano, 2012).

En el presente trabajo nos centraremos en el análisis del turismo de luna de miel para el turista chino. Cabe destacar la importancia del mismo, ya que la revisión de la literatura nos muestra que se han publicado recientemente artículos sobre turismo chino en España y Europa (Andreu, Claver y Quer, 2013; Andreu, Claver y Quer, 2014; Lojo, 2016; Lojo y Cànoves, 2015), pero ninguno de ellos ha tratado el turismo chino de luna de miel.

Desde 2012, China es el mayor mercado turístico emisor del mundo (OMT, 2016) $\mathrm{y}$, aunque el turismo es el motor económico de España, no aparece en la lista de los 20 principales destinos internacionales del turismo chino en 2015 (CNTAIC, 2016). En estos años, España sigue buscando la cooperación con China para atraer a los turistas chinos 
(Ministerio de Energia, Turismo y Agenda Digital, 2010; González, 2015; Minmin, 2015), y el turismo de luna de miel puede ser un buen proyecto de cooperación considerando que el viaje de luna de miel se está convirtiendo en una moda entre los turistas chinos (Lojo y Cànoves, 2015; Vizcaíno, 2016; Li, 2016). Por ello, es importante entender el pensamiento y el comportamiento de los turistas chinos en el viaje de luna de miel.

El objetivo general del presente trabajo es la elaboración de un estudio teórico relativo al turismo chino de luna de miel para que las empresas o las ciudades mejoren la competitividad aprovechando este sector emergente. De este objetivo general se derivan tres objetivo específicos. (i) Definir las características del turismo de luna de miel en un marco de turismo alternativo. (ii) Identificar los principales atributos del destino turístico en general, y del destino de luna de miel en particular. (iii) Conocer las características del turista chino en el turismo internacional y europeo.

Para alcanzar los objetivos expuestos, se planteó la siguiente estructura: tras la breve introducción y metodología, se resumen las definiciones del turismo alternativo y su clasificación conceptual. A continuación, se propone una aproximación a las características especiales del turismo de luna de miel. Seguidamente, se trata de estudiar el proceso de la elección del destino turístico, especialmente los atributos del destino que lo hacen más atractivo. Luego, se describe detalladamente el perfil de los turistas chinos en el mercado internacional, sus destinos preferidos, y cómo piensan y se comportan en sus viajes internacionales. Finalmente, se establecen las principales conclusiones.

\section{METODOLOGÍA}

La metodología utilizada en esta investigación se basa en la revisión bibliográfica en dos fases. En una primera etapa se realiza una revisión, a nivel nacional e internacional, de la literatura académica existente sobre el turismo alternativo, prestando especial atención al turismo de luna de miel y a la elección del destino. Esta fase permite adoptar parte de las consideraciones realizadas por diversos autores (Cohen, 1989; Osorio, 2010; Gard McGehee, 2002; Winchester, Winchester y Alvey, 2011, entre otros), conocer los avances publicados, metodologías utilizadas o las conclusiones a las que llegaron. Se ha realizado una profunda búsqueda de artículos científicos, libros, tesis y ponencias referentes a esta temática, de los cuales sólo se comentan en este trabajo una selección de los más relevantes y representativos. No se ha limitado la búsqueda a revistas turísticas, debido a la relativa escasez de revistas turísticas de reconocido prestigio internacional (Benckendorff, 2009); y a que las investigaciones en turismo nacionales se recogen en revistas de diferentes disciplinas (Sancho, 2006). Sin embargo, sí se centra la búsqueda en el campo de las ciencias humanas y sociales.

Pese a que la investigación científica en el ámbito turístico se está consolidando a nivel nacional e internacional (Albacete y Fuentes, 2010), es escasa la literatura académica sobre algunos tipos concretos de turismo alternativo, como es el caso del turismo de luna de miel.

De ahí la necesidad de desarrollar una segunda etapa en la que se realiza una revisión webgráfica para la recopilación de noticias de prensa, datos estadísticos (INE y Quandl), recursos web y estudios e informes del mercado turístico chino. 
La elección de las fuentes depende de las cuestiones a investigar: (i) ¿Cuáles son las características del turismo de luna de miel en un marco de turismo alternativo? (ii) ¿cuáles son los principales atributos del destino de luna de miel? (iii) ¿Cómo es el turista chino en el turismo internacional y europeo? Por lo que, aunque se podían consultar fuentes en idioma chino, las mismas tenían su versión en inglés y es la que ha sido citada para facilitar la difusión de la presente investigación, lo que supone una ventaja, llegando así a un número mayor de investigadores Españoles y Europeos.

\section{TURISMO ALTERNATIVO}

En este punto nos aproximamos conceptualmente al turismo alternativo como marco teórico en el que se integra el turismo de luna de miel. Así, se define el turismo alternativo para, a continuación, resumir los tipos de turismo alternativo revisados en la literatura.

\subsection{Definición de turismo alternativo}

La evolución del turismo implica un cambio en las motivaciones de la demanda turística (Bouchet, Lebrun y Auvergne, 2004) y en las tendencias de consumo de los turistas (Armadans, 1999). Un factor clave en el desarrollo del turismo ha sido la evolución que ha sufrido tanto la demanda del sector como las tendencias sociales. Sin embargo, es poca la información acerca de algunos tipos de turismo alternativo, entendido éste como las nuevas formas de turismo que han surgido como oportunidades de negocio para satisfacer los nuevos gustos y preferencias de los turistas. Así, estas tendencias en turismo que se aprecian en la actualidad, justifican la aparición de nuevos tipos de turismo alternativo y de corta duración (McDonald y Murphy, 2008). De ahí, la evolución de los destinos del turismo de masas (Ivars, Rodríguez y Vera, 2013) y la proyección del turismo alternativo centrado en otros tipos de turismo. Según concluye Osorio (2010) en su investigación, el turismo de masas y el alternativo no son necesariamente modelos consecutivos, aunque sí presentan una forma diferenciada de practicar el turismo, siendo este último extremadamente variado y complejo (Cohen, 1989).

En ocasiones, se propone el turismo alternativo como solución a los problemas del turismo de masas (Cazes, 1989). A pesar de ello, según Cohen (1989) se debe tener en cuenta que la crítica al turismo de masas hace que las expectativas del turismo alternativo sean demasiado altas y por tanto irreales. En ocasiones, el turismo de masas destruye cultura y sociedad local, y en otras contribuye a preservarla y crear nuevas. Por ello, Cohen (1989) apuesta por una reforma para hacer un turismo de masas más apropiado, alejándose de la crítica radical que apunta a que es obsoleto y poco convincente.

Llegados a este punto, es importante definir ambos tipos de turismo, tomando como base la investigación de Osorio (2010), y sus características propias.

El turismo de masas (fordista o industrial), se define como una producción en cadena de productos turísticos estandarizados (en forma, tiempo y territorio) para su consumo masificado e impersonal, creando un comportamiento del turista pasivo, de descanso, básicamente de observación. En un mercado manejado por empresas oligopólicas, muy 
concentrado temporal (estacionalidad) y espacialmente. Supone un impacto negativo en el ambiente natural y, muy frecuentemente, en los espacios subdesarrollados, propiciando el deterioro social (Osorio, 2010:250).

Por su parte, el turismo alternativo (posfordista o postindustrial) promueve estructuras de viaje más flexibles y heterogéneas en distintos espacios naturales (áreas naturales protegidas y no protegidas) y artificiales (urbanos y rurales) que diversifican la organización de las empresas turísticas, y, particularmente en los países subdesarrollados, reconoce e incorpora a la población local como un actor social necesario en dicha organización. Esta incorporación hace pensable un mayor control sobre los impactos ambientales, económicos y sociales que se suscitan en los destinos turísticos (Osorio, 2010:251).

En la Tabla 1, se resumen las principales diferencias entre el turismo alternativo y el turismo de masas convencional.

\section{Tabla 1 \\ CARACTERÍSTICAS DEL TURISMO DE MASAS Y DEL TURISMO ALTERNATIVO}

\begin{tabular}{|c|c|c|}
\hline Dimensión & Turismo de masas & Turismo alternativo \\
\hline \multirow{6}{*}{$\begin{array}{l}\text { Estrategias de } \\
\text { desarrollo }\end{array}$} & $\begin{array}{l}\text { Gran escala (p.e. expansión de } \\
\text { construcciones e infraestructuras). }\end{array}$ & $\begin{array}{l}\text { Pequeña escala (p.e. expansión de } \\
\text { construcciones e infraestructuras). }\end{array}$ \\
\hline & $\begin{array}{l}\text { Distribución espacial de turistas } \\
\text { e infraestructuras con alta } \\
\text { concentración. }\end{array}$ & $\begin{array}{l}\text { Distribución espacial de turistas e } \\
\text { infraestructuras dispersos. }\end{array}$ \\
\hline & Alteración del paisaje. & Poca alteración del paisaje. \\
\hline & $\begin{array}{l}\text { Sobresaturación de la capacidad de } \\
\text { carga. }\end{array}$ & Respeto de la capacidad de carga. \\
\hline & Estacionalidad alta. & Estacionalidad baja no tan marcada. \\
\hline & $\begin{array}{l}\text { Interés bajo en SIT (special interest } \\
\text { tourist) }\end{array}$ & $\begin{array}{l}\text { Interés alto en SIT (special interest } \\
\text { tourist) }\end{array}$ \\
\hline \multirow{8}{*}{ Oferta turística } & $\begin{array}{l}\text { Inversiones y/o operadores } \\
\text { extranjeros. }\end{array}$ & Inversiones y/o operadores locales. \\
\hline & $\begin{array}{l}\text { Empresas grandes (cadenas o } \\
\text { multinacionales) }\end{array}$ & Empresas pequeñas y medianas \\
\hline & Oferta estandarizada y homogénea. & Oferta especializada. \\
\hline & Bajos niveles de autenticidad. & Altos niveles de autenticidad. \\
\hline & Baja diferenciación del producto. & Alta diferenciación del producto. \\
\hline & $\begin{array}{l}\text { Relación calidad precio centrada en } \\
\text { precio. }\end{array}$ & $\begin{array}{l}\text { Relación calidad precio centrada en } \\
\text { calidad. }\end{array}$ \\
\hline & Empleados sin formación. & $\begin{array}{l}\text { Empleados con formación } \\
\text { (ambiental). }\end{array}$ \\
\hline & $\begin{array}{l}\text { Números altos de paquetes turísticos } \\
\text { (relativo al total de número de } \\
\text { visitantes y absoluto). }\end{array}$ & $\begin{array}{l}\text { Números bajos de paquetes turísticos } \\
\text { (relativo al total de número de } \\
\text { visitantes y absoluto). }\end{array}$ \\
\hline
\end{tabular}




\begin{tabular}{|c|c|c|}
\hline Dimensión & Turismo de masas & Turismo alternativo \\
\hline \multirow{6}{*}{ Demanda turística } & Turistas pasivos (p.e. sol y playa). & Turistas activos (p.e. deportes). \\
\hline & Grupos grandes. & $\begin{array}{l}\text { Grupos reducidos y viajeros } \\
\text { individuales }\end{array}$ \\
\hline & $\begin{array}{l}\text { Numero alto de turistas (absoluto y } \\
\text { relativo a la población). }\end{array}$ & $\begin{array}{l}\text { Numero bajo de turistas } \\
\text { (absoluto y relativo a la } \\
\text { población). }\end{array}$ \\
\hline & Programa organizado. & Programa personalizados. \\
\hline & $\begin{array}{l}\text { Alta de interés en entorno y cultura } \\
\text { locales. }\end{array}$ & $\begin{array}{l}\text { Interés en entorno y cultura } \\
\text { locales. }\end{array}$ \\
\hline & Contacto con el entorno artificial. & $\begin{array}{l}\text { Contacto con el entorno natural } \\
\text { y la población local. }\end{array}$ \\
\hline \multirow{8}{*}{$\begin{array}{l}\text { Dimensiones del } \\
\text { entorno }\end{array}$} & $\begin{array}{l}\text { Niveles altos de dependencia en } \\
\text { financiación e inversión externa. }\end{array}$ & $\begin{array}{l}\text { Niveles bajos de dependencia } \\
\text { en financiación e inversión } \\
\text { externa. }\end{array}$ \\
\hline & $\begin{array}{l}\text { Bajo retorno económico a la } \\
\text { comunidad de destino. }\end{array}$ & $\begin{array}{l}\text { Alto retorno económico a la } \\
\text { comunidad de destino. }\end{array}$ \\
\hline & $\begin{array}{l}\text { Presiones altas en el entorno socio } \\
\text { cultural. }\end{array}$ & $\begin{array}{l}\text { Presiones altas en el entorno } \\
\text { socio cultural. }\end{array}$ \\
\hline & $\begin{array}{l}\text { Alta dependencia del desarrollo } \\
\text { del mercado o de los mercados } \\
\text { maduros. }\end{array}$ & $\begin{array}{l}\text { Baja dependencia del desarrollo } \\
\text { del mercado o de los mercados } \\
\text { maduros. }\end{array}$ \\
\hline & $\begin{array}{l}\text { Poder de mercado alto de } \\
\text { los operadores turísticos } \\
\text { internacionales. }\end{array}$ & $\begin{array}{l}\text { Poder de mercado bajo de } \\
\text { los operadores turísticos } \\
\text { internacionales. }\end{array}$ \\
\hline & $\begin{array}{l}\text { Bajo grado del control del destino de } \\
\text { la cadena de valor y los canales de } \\
\text { distribución. }\end{array}$ & $\begin{array}{l}\text { Alto grado del control del } \\
\text { destino de la cadena de valor y } \\
\text { los canales de distribución. }\end{array}$ \\
\hline & $\begin{array}{l}\text { Niveles medio-bajos de beneficio y } \\
\text { educación del mercado. }\end{array}$ & $\begin{array}{l}\text { Niveles medio-altos de } \\
\text { beneficio y educación del } \\
\text { mercado. }\end{array}$ \\
\hline & Baja movilización social. & $\begin{array}{l}\text { Alta movilización social. Poder } \\
\text { para cambiar individuos. }\end{array}$ \\
\hline
\end{tabular}

Fuente: Fullana, Palmer y Ayuso (2002), Gard McGehee (2002) y Cooper y Hall (2008).

\subsection{Tipos de turismo alternativo}

Mowforth (1993) citado en Bueno, Menéndez, y García (1995) resume las modalidades de turismo que pertenecen a turismo alternativo (véase Tabla 2), y las distingue entre los siguientes cuatro tipos (véase Tabla 3 ):

a) Turismo ecológico, en el que las actividades realizadas están relacionadas con la naturaleza.

b) Turismo cultural, en el que el turista realiza actividades para conocer la cultura del destino visitado. 
c) Turismo de aventuras, en el que existen las actividades deportivas o cierto riesgo.

d) Turismo especializado, en el que el turista realiza el viaje por un objetivo específico o en un campo académico específico.

Tabla 2

MODALIDADES DE TURISMO ALTERNATIVO

\begin{tabular}{|l|l}
\hline Turismo alternativo & Turismo de diseño \\
Eco-turismo & Turismo duro \\
Turismo ecológico & Turismo blando \\
Turismo sostenible & Turismo de riesgo \\
Turismo medioambiental & Turismo de aventura \\
Turismo natural & Turismo cultural \\
Turismo verde & Turismo étnico \\
Turismo científico & Antro-turismo \\
Turismo rural & Agro-turismo \\
Turismo de casitas de campo & Turismo arqueológico \\
Turismo de granjas & Turismo especialista \\
Turismo salvaje & Turismo de contacto \\
Turismo de safari & Caravaning \\
Turismo de campings & Etc. \\
\hline
\end{tabular}

Fuente: Mowforth, (1993) citado en Bueno, Menéndez y García (1995).

Tabla 3

CLASIFICACIÓN DE MODALIDADES DE TURISMO ALTERNATIVO

\begin{tabular}{|l|l|l|l|l|}
\hline NIVEL 1 & \multicolumn{3}{|c|}{ ALTERNATIVO } \\
\hline NIVEL 2 & Ecológico & Cultural & Aventuras & Especializado \\
\hline NIVEL 3 & Natural & Antro-turismo & Riesgo & Académico \\
& Safari & Arqueológico & Safari & Agrícola \\
& Salvaje & Granjas & Deportivo & Científico \\
& etc. & Rural & Salvaje & etc. \\
& & etc. & etc. & \\
\hline
\end{tabular}

Fuente: Mowforth, (1993) citado en Bueno, Menéndez, y García (1995).

Para esta clasificación, Bueno, Menéndez y García (1995) indican que las diferentes categorías no son excluyentes entre sí. Es decir, por ejemplo, el turismo salvaje, como está muy relacionado con la naturaleza y al mismo tiempo dispone de cierto riesgo, se puede incluir en turismo ecológico y también en turismo de aventuras.

En base a lo revisado en este punto, podemos ubicar el turismo de luna de miel como un turismo alternativo (primer nivel) especializado (segundo nivel). 


\section{TURISMO DE LUNA DE MIEL}

Una vez analizado el concepto de turismo alternativo y sus modalidades, a continuación, se centra la atención en el concepto de turismo de luna de miel.

La luna de miel se refiere a las vacaciones que realizan los novios recién casados para celebrar su matrimonio y compromiso de vida juntos (Winchester, Winchester, y Alvey, 2011). En la cultura europea, la costumbre de que los recién casados vayan juntos de vacaciones se origina de Gran Bretaña a principio del Siglo XIX, cuando las parejas de clase alta solían hacer un viaje nupcial, a veces acompañados de los amigos o la familia, para visitar a los familiares que no habían podido acudir a la boda. Desde los años 20 esta costumbre se extiende al continente europeo y se conoce en Francia como "viaje de estilo inglés". La típica luna de miel empieza en la medianoche. Cuando se casan, los novios se van de la ceremonia para coger un tren o barco. Sin embargo, hoy en día muchas parejas no inician su viaje hasta 1-3 días después de la ceremonia (Vodenska, 2013). Este viaje se considera un excelente punto de partida para la vida matrimonial y constituye el momento en el que muchas parejas planifican su futura vida en común (Kim y Agrusa, 2005; Squillaro, 2006).

\subsection{Características del viaje de luna de miel}

El viaje de luna de miel tiene varias características especiales que lo hacen diferente de otros tipos de viajes. En la Tabla 4, se listan los argumentos de los profesionales sobre el viaje de luna de miel. De acuerdo con estos argumentos, en la presente investigación proponemos 5 características principales del viaje de luna de miel: larga duración y planificación, temporada propia, público objetivo joven, necesidades particulares, toma de decisión compartida.

\section{Tabla 4}

\section{LAS CARACTERÍSTICAS Y LOS ARGUMENTOS DEL VIAJE DE LUNA DE MIEL}

\begin{tabular}{|l|l|l|}
\hline CARACTERÍSTICAS & \multicolumn{1}{|c|}{ ARGUMENTOS } & \multicolumn{1}{|c|}{ AUTORES } \\
\hline \multirow{5}{*}{ Larga duración } & $\begin{array}{l}\text { Los viajes de los novios españoles tienen } \\
\text { una duración en promedio de 10 días. }\end{array}$ & Ligerini (2014) \\
\cline { 2 - 3 } Larga planificación & $\begin{array}{l}\text { Los viajes de luna de miel de las parejas de } \\
\text { China en Europa tienen una duración media } \\
\text { de 10 o 12 días. }\end{array}$ & $\begin{array}{l}\text { Agencia EFE } \\
(2014)\end{array}$ \\
\hline & $\begin{array}{l}\text { El viaje siempre requiere varios meses de } \\
\text { preparación. }\end{array}$ & Pulido (2014) \\
\cline { 2 - 3 } & $\begin{array}{l}\text { No existen ofertas de última hora para este } \\
\text { tipo de vacaciones. }\end{array}$ & Bueno (2014) \\
\hline
\end{tabular}




\begin{tabular}{|c|c|c|}
\hline CARACTERÍSTICAS & ARGUMENTOS & AUTORES \\
\hline \multirow[t]{2}{*}{ Propia temporada } & $\begin{array}{l}\text { Hay dos picos en el año. El primero, durante } \\
\text { los meses de mayo, junio y julio, y el segun- } \\
\text { do, en septiembre y octubre. }\end{array}$ & $\begin{array}{l}\text { Palladino } \\
(2014)\end{array}$ \\
\hline & $\begin{array}{l}\text { La mayoría de los novios aprovechan la } \\
\text { primavera y el final del verano para casarse. }\end{array}$ & Pulido (2014) \\
\hline Jóvenes & $\begin{array}{l}\text { La edad promedia del primer matrimonio es } \\
\text { de entre } 25 \text { y } 35 \text {, para el hombre, y de entre } \\
22 \text { y } 32 \text {, para la mujer. }\end{array}$ & Quandl (2015) \\
\hline \multirow{2}{*}{$\begin{array}{l}\text { Necesidades } \\
\text { particulares }\end{array}$} & $\begin{array}{l}\text { Casi todas las navieras ofrecen el servicio } \\
\text { para realizar la boda o la renovación de } \\
\text { compromiso a bordo de un crucero aunque } \\
\text { no tiene validez legal. }\end{array}$ & Lunar (2014) \\
\hline & $\begin{array}{l}\text { Buscan el equilibrio entre emociones fuertes } \\
\text { y relax, eligiendo destinos que ofrecen una } \\
\text { experiencia muy especial. }\end{array}$ & $\begin{array}{l}\text { Lucena (2015) } \\
\text { Vodenska } \\
(2013)\end{array}$ \\
\hline \multirow{5}{*}{$\begin{array}{l}\text { Decisión de } \\
\text { dos personas }\end{array}$} & $\begin{array}{l}\text { El conflicto de distintas opiniones marca la } \\
\text { decisión del grupo. }\end{array}$ & $\begin{array}{l}\text { Jang. et al. } \\
(2006)\end{array}$ \\
\hline & $\begin{array}{l}\text { En la decisión del grupo, la interacción de } \\
\text { cada miembro influye en la decisión final. }\end{array}$ & $\begin{array}{l}\text { Jang. et al. } \\
(2006)\end{array}$ \\
\hline & $\begin{array}{l}\text { La mayoría de las parejas hacen concesiones } \\
\text { para resolver sus discrepancias en la toma } \\
\text { de decisión. }\end{array}$ & $\begin{array}{l}\text { Kirchler } \\
(1993)\end{array}$ \\
\hline & $\begin{array}{l}\text { Una parte de la pareja no puede ignorar fá- } \\
\text { cilmente la opinión de la otra cuando la otra } \\
\text { tiene una fuerte preferencia positiva a una } \\
\text { alternativa particular. }\end{array}$ & Park (1982) \\
\hline & $\begin{array}{l}\text { El conflicto se resuelve por la búsqueda de } \\
\text { alternativas hasta que el nivel mínimo de ex- } \\
\text { pectativas de ambos está satisfecho. }\end{array}$ & $\begin{array}{l}\text { Jang. et al. } \\
(2006)\end{array}$ \\
\hline
\end{tabular}

Fuente: elaboración propia.

A continuación, se explican más detalladamente cada una de las 5 características propuestas.

\subsubsection{Larga planificación y larga duración}

La luna de miel, al igual que la boda, es un evento único para la mayoría de las personas, un evento que los novios han soñado durante mucho tiempo y quieren recordar para toda la vida. Distinto de otros tipos de viaje, el viaje de luna de miel se realiza en un 
destino especial y con larga duración. Los novios prefieren ir a los lugares a los que no van normalmente, o no han podido ir por razón de presupuesto o tiempo. Normalmente son lugares lejanos o de otro continente (Vodenska, 2013).

Asimismo, la luna de miel siempre dura más tiempo que otros viajes. Según Ligerini (2014), la directora de marketing y ventas de Jetmar viajes, los viajes de los novios españoles tienen una duración en promedio de diez días, pero la cantidad puede variar según el destino, pasando una semana como mínimo. En cuanto a la situación de los turistas chinos, los viajes de luna de miel de las parejas de China en Europa tienen una duración de media de diez o doce días (diariosur.es, 2014). Pese a que no hay estudios que comparan directamente la duración media de los turistas chinos que viajan a Europa por motivo de su luna de miel con respecto a otros motivos, podemos afirmar que la duración media es mayor para los viajes de luna de miel, ya que la media por otros motivos es de 9 días (Andreu, Claver y Quer, 2013; Andreu, Claver y Quer, 2014; Lojo, 2016; Lojo y Cànoves, 2015).

Por su particularidad e importancia, el viaje de luna de miel siempre requiere varios meses de preparación, una alta involucración por parte de la pareja y suele gestionarse a través de agencias de viajes comprando paquetes organizados (Pulido, 2014; Vodenska, 2013). Por ello, en las agencias de viajes, casi no existen ofertas de última hora para este tipo de viajes (Bueno, 2014).

\subsubsection{Temporada de viaje}

El momento en el que las parejas suelen realizar su luna de miel es diferente en los distintos países. Por un lado, la costumbre y cultura particulares de cada país determina la elección de la fecha para la boda. En China, se fija según el calendario lunar. El criterio es evitar fechas que no sean favorables para los novios, sus padres, sus futuros hijos; en cualquier ámbito, sea en el trabajo o sea en la vida cotidiana. Por el contrario, en España no existe esta superstición. La mayoría de los novios aprovechan la primavera y el final del verano para casarse, porque las temperaturas bajas imposibilitan el lucimiento de los novios e invitados (Pulido, 2015). Otra consideración de los españoles para fijar la fecha de boda es la lista de espera de los lugares para realizar la ceremonia y el banquete, si lo que prefieren es celebrarlo en un lugar de moda en una gran ciudad.

Por otro lado, la diferencia del momento de realizar el viaje de luna de miel también proviene de la política, especialmente la política de vacaciones. Por ejemplo, en España, que se considera uno de los países con más vacaciones, según la ley laboral (R.D.LG. 1/95, art. 38), la duración de las vacaciones puede establecerse por pacto entre las partes, trabajador y empresario, o por convenio colectivo, sin que en ningún caso este tiempo pueda ser inferior a 30 días naturales. Además, los recién casados tienen un permiso de matrimonio de quince días naturales. Bajo estas políticas, los novios de España tienen más flexibilidad para realizar su luna de miel en el tiempo que prefieran. Comparándolo con China, el permiso de matrimonio para una pareja normalmente es de tres días. Si la persona tiene 3 años más de la edad legal del matrimonio, disfruta unos días más de permiso. Por eso, la luna de miel de China se hace principalmente coincidiendo con las fiestas nacionales tales como fiesta de la primavera, día nacional y día de trabajo. 
Por lo tanto, cada país tiene su propia temporada de luna de miel por su especial cultura y política. Palladino (2014), cofundadora de Pasifika, agencia boutique especializada en paquetes turísticos a medida, puntualiza que en España: "hay dos picos en el año. El primero, durante los meses de mayo, junio y julio, y el segundo, en septiembre y octubre“ (cincodias.com, 2014).

\subsubsection{Peculiaridad de la edad}

En general, las parejas se están casando más tarde, observándose una tendencia a que la edad aumente debido a matrimonios posteriores y segundos matrimonios (Vodenska, 2013). Según los datos de Age at First Marriage - Female By Country (Gráfico 2) y Age at First Marriage - Male By Country (Gráfico 3) de Quandl (2015) (última actualización disponible), en la mayoría de los países del mundo la edad media del primer matrimonio es de entre 25 y 35 años, para el hombre, y de entre 22 y 32 años, para la mujer. Generalmente, la gente de Europa y América se casa más tarde que la gente de Asia.

De acuerdo con los datos de INE (2017), este trabajo selecciona China junto con los 15 países, cuyos turistas ocupan más de $1 \%$ de todos los visitantes no residentes en España que entran en el país (Gráfico 1). Se ve más claro en los gráficos 2 y 3 que los protagonistas del viaje de luna de miel son bastante jóvenes, y para los turistas que llegan a España según país, la mayoría de ellos tiene una edad comprendida entre 24 y 36 años.

\section{Gráfico 1 \\ ENTRADA DE TURISTAS SEGÚN PAÍS}

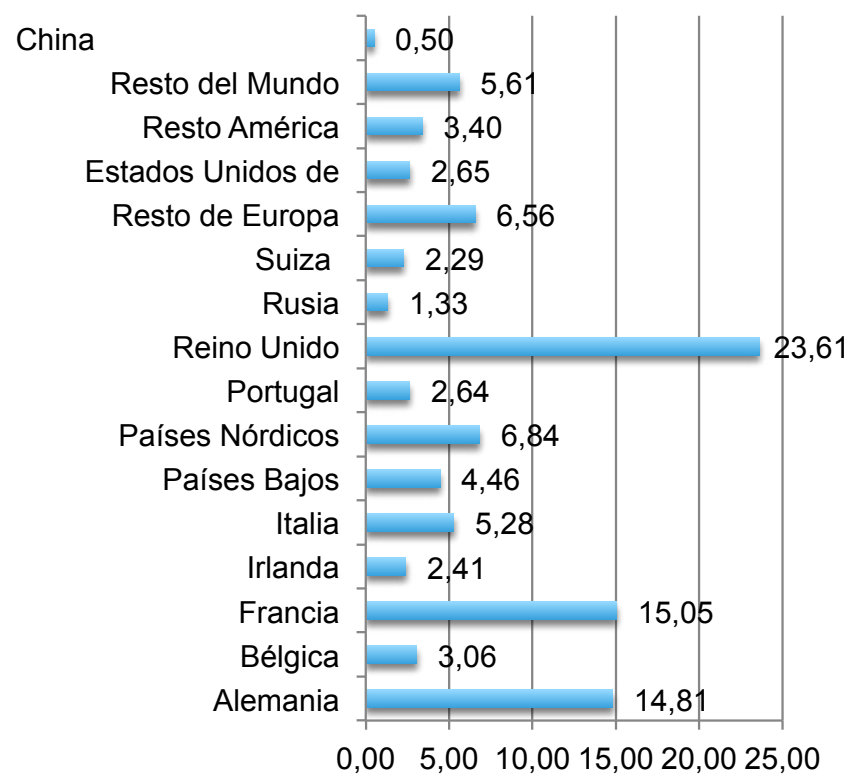

Fuente: elaboración propia a partir de INE (2017). 


\section{Gráfico 2 \\ EDAD MEDIA DEL PRIMER MATRIMONIO DE LAS MUJERES SEGÚN PAÍS}

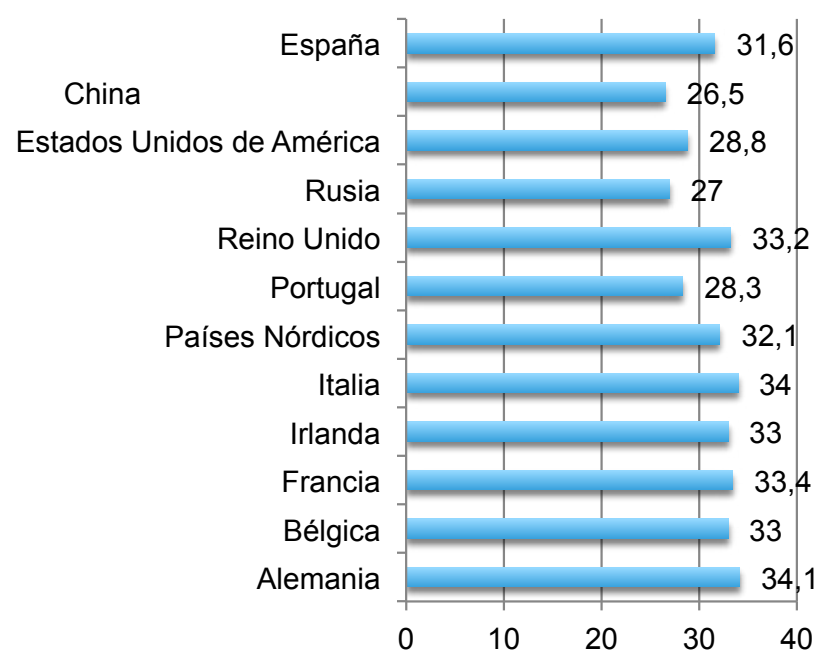

Fuente: elaboración propia a partir de Quandl (2015).

\section{Gráfico 3 \\ EDAD MEDIA DEL PRIMER MATRIMONIO DE LOS HOMBRES SEGÚN PAÍS}

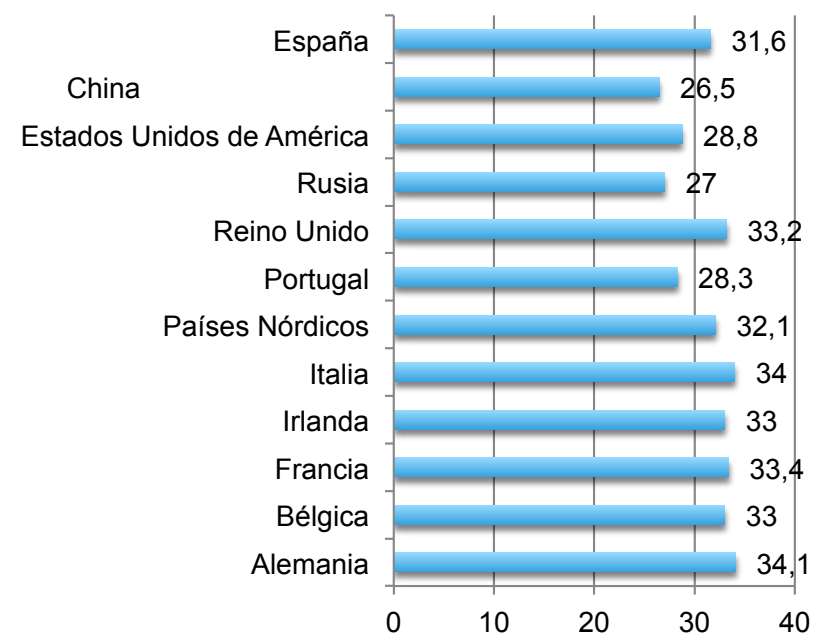

Fuente: elaboración propia a partir de Quandl (2015). 


\subsubsection{Necesidades particulares}

Diferentes de otros tipos de turistas, las parejas en el viaje de luna de miel tienen necesidades particulares. Lo fundamental que los novios buscan es un entorno romántico. Además del romanticismo, cada vez más turistas están buscando unas experiencias únicas y singulares que les dejen un recuerdo imborrable. Así, este tipo de turistas muestran preferencias por actividades diferentes de acuerdo a su motivación personal, sus valores, su experiencia previa o las recomendaciones de su grupo de referencia (Kim \& Agrusa, 2008). Por ejemplo, hay novios que prefieren una escapada por Europa, o los que se decantan por Argentina (si se casan en invierno), o los que disfrutan de los safaris en África, o los que optan por una travesía de lujo en pequeños barcos por el Amazonas peruano y Vietnam. Es decir, hoy en día, a los novios lo que les importa es el equilibrio entre emociones fuertes y relax romántico (Lucena, 2015).

Debido a la significación conmemorativa de la luna de miel los turistas se vuelven más exigentes en los servicios, comparando con otros tipos de turismo (excepto el turismo de lujo). Nadie quiere escatimar en su luna de miel. Hospedaje de lujo, cenas íntimas, y masajes relajantes se encuentran en lo más alto de la lista de deseos de casi todos los recién casados. De hecho, hay estudios que muestran que las parejas estiran el presupuesto en la luna de miel, o están menos preocupados por el coste de su viaje, ya que la mayoría lo ven como una experiencia única en la vida (Vodenska, 2013; Winchester, Winchester y Alvey, 2011).

Existen unas ofertas especiales dirigidas al turismo de luna de miel. Por ejemplo, los Hoteles Only Adults (sólo para adultos), cuyas características principales son el relax, el lujo y la tranquilidad. En este tipo de hotel, todo está enfocado al disfrute de la pareja, por lo que estos hoteles son perfectos para los recién casados (ABC.es, 2014; Vallano, 2012). Además, los servicios alrededor de la boda también son típicos en el turismo de luna de miel, como la ceremonia religiosa, los servicios de wedding planners y fotógrafos especializados (álbum de fotos y vídeos de bodas). Casi todas las navieras ofrecen el servicio para realizar la boda o la renovación de compromiso a bordo de un crucero aunque no tiene validez legal, indica Lunar (2014), experta en cruceros de Nautalia.

\subsubsection{Decisión en pareja}

La toma de decisiones se puede dividir básicamente en dos tipos, la decisión individual y la decisión del grupo, entre las dos tipologías existen muchas diferencias. El conflicto de distintas opiniones marca la decisión del grupo (Jang. et al., 2006). En cuanto al turismo, la decisión del grupo se hace en la mayoría de los viajes siempre que no sea un viaje unipersonal. Cuando se está ante una decisión de grupo, el individuo comunica e interacciona con los demás en el proceso de la toma de decisiones, y la interacción influye en la decisión final (Jang. et al., 2006).

La decisión del viaje de luna de miel es un proceso que involucra a dos personas (Winchester, Winchester y Alvey, 2011), y si existen discrepancias, se puede llegar a una decisión consensuada en la que ambos miembros estén de acuerdo. El conflicto se resuelve con la búsqueda de alternativas hasta que el nivel mínimo de expectativas de ambos se 
satisface (Jang. et al., 2006). Como cada individuo tiene su propia preferencia y objetivo, los componentes de la pareja siempre comparten su deseo en varias alternativas (Spiro, 1983). Sin embargo, la mayoría de las parejas hacen concesiones mutuas para resolver sus discrepancias en la toma de decisión (Kirchler, 1993). Una de las características más significativas de la decisión en pareja es que una parte de la pareja no puede ignorar fácilmente la opinión de la otra parte cuando ésta tiene una fuerte preferencia positiva a una alternativa particular (Park, 1982). Por ejemplo, uno puede incluir las preferencias del otro en su decisión y este último puede cambiar su preferencia para no afectar los sentimientos del primero.

En resumen, el turismo de luna de miel es un tipo de turismo en el que las parejas planifican con mucha antelación y deciden juntos un viaje de larga distancia y larga duración, lo realizan después de la boda para celebrar su matrimonio y pasar un tiempo romántico e íntimo. Durante el viaje, las parejas ofrecen una demanda específica y una actitud más exigente hacia los servicios y aceptan un precio relativamente alto.

\section{ELECCIÓN DE DESTINO TURÍSTICO}

Conocer cómo piensan y cómo se comportan los turistas en el proceso de la elección del destino turístico ayuda el mejor desarrollo del mismo. En esta parte, primero, se presenta brevemente el proceso de la decisión turística y se destacan los atributos del destino, que son determinantes para la atracción del destino, para después poner la atención en el destino de turismo de luna de miel.

Cuando los turistas realizan un viaje se mueven por sus necesidades y motivaciones para tomar la primera decisión de si ir (o no) de viaje. Después, influyen los atributos del destino para tomar la segunda decisión de adónde ir de viaje (Dann, 1977). En general, los turistas, después de identificar sus motivaciones de viaje, recogen información de las diferentes alternativas y llevan a cabo una serie de decisiones sobre el destino, la forma y el tiempo. Dado que el destino turístico es el corazón en toda actividad turística y en su elección generalmente influyen otras decisiones conexas, la elección de destino se puede considerar el núcleo de la decisión consumidora turística (Wei-na, 2011).

La elección de un destino turístico contiene dos etapas. La primera etapa es obtener un conjunto de las alternativas de destinos turísticos y el siguiente paso es seleccionar un destino final desde este conjunto (Um y Crompton, 1990). Los turistas no muestran el mismo interés por cada alternativa, debido a la variedad de atributos considerados y a otros factores subjetivos (Lazzari, 2006). Es decir, no todos los destinos son igualmente atractivos para los turistas. Existen unos destinos más atractivos que otros.

Los atributos del destino (componentes que construyen un destino) se pueden considerar determinantes para la atracción del destino (Formica y Uysal, 2006; Gearing, Swart, y Var, 1974; Hu y Ritchie, 1993; Kim, 1998). Sin embargo, unos atributos pueden ser más atractivos que otros para los turistas. En el proceso de la elección del destino, las personas evalúa varios atributos de todas las alternativas potenciales y seleccionan el destino final con los atributos que optimizan los beneficios (Kim y Agrusa, 2005). Por lo tanto, es importante identificar los atributos que hacen que los turistas elijan un destino en vez de otro. 
Law (1995) clasifica los atributos del destino en dos categorías principales. La primera incluye las características innatas tales como clima, ecología, recursos naturales, alimentos, cultura y arquitectura histórica. La segunda categoría es aquella que se ha desarrollado particularmente para los turistas como hoteles, resorts, restauración, transporte y entretenimiento. Desde otro punto de vista, las características del destino también se pueden categorizar según las características de los recursos tales como cultural/histórico, natural, evento, deportivo y entretenimiento (Goeldner y Ritchie 2006).

Lee, Huang, y Chen (2010) resumen la variedad de atributos del destino empleados frecuentemente en la literatura (Véase Tabla 5).

\section{Tabla 5}

\section{INVESTIGACIONES PREVIAS SOBRE LOS ATRIBUTOS DEL DESTINO TURÍSTICO}

\begin{tabular}{|c|c|c|}
\hline Autores & Objetivo de Investigación & Atributos del destino turístico \\
\hline $\begin{array}{r}\text { Gearing et al. } \\
(1974)\end{array}$ & $\begin{array}{l}\text { Investigar los recursos y los } \\
\text { lugares de interés del destino } \\
\text { que atraen a los turistas; explo- } \\
\text { rar la percepción de los turistas } \\
\text { para un destino }\end{array}$ & $\begin{array}{l}\text { Natural; social; histórico; recreación y com- } \\
\text { pra; infraestructura; alimentos y alojamiento. }\end{array}$ \\
\hline $\begin{array}{r}\text { Ritchie y Zins } \\
(1978)\end{array}$ & $\begin{array}{l}\text { Explorar la percepción de los } \\
\text { turistas para un destino }\end{array}$ & $\begin{array}{l}\text { La belleza natural y el clima: las característi- } \\
\text { cas culturales y sociales; accesibilidad de la } \\
\text { región; actitudes hacia los turistas; infraes- } \\
\text { tructura de la región; los niveles de precios; } \\
\text { instalaciones comerciales y de compra; de- } \\
\text { portes, recreación e instalaciones educativas. }\end{array}$ \\
\hline Ferrario (1979) & $\begin{array}{l}\text { Investigar los recursos y los } \\
\text { lugares de interés del destino } \\
\text { que atraen a los turistas }\end{array}$ & $\begin{array}{l}\text { Características ambientales típicas: el paisaje, } \\
\text { la fauna, la vegetación natural. } \\
\text { La población local y las formas típicas de la } \\
\text { vida. } \\
\text { Instalaciones turísticas, deportes y activida- } \\
\text { des de recreación. }\end{array}$ \\
\hline $\begin{array}{r}\text { Hu y Ritchie } \\
\text { (1993) }\end{array}$ & $\begin{array}{l}\text { Explorar la percepción de los } \\
\text { turistas para un destino }\end{array}$ & $\begin{array}{l}\text { Clima; disponibilidad / calidad de los aloja- } \\
\text { mientos; deportes / oportunidades de recrea- } \\
\text { ción; paisaje; alimentos; entretenimiento; } \\
\text { singularidad de la vida de la población local; } \\
\text { lugares de interés histórico; museos, lugares } \\
\text { de interés cultural; dificultades de la comu- } \\
\text { nicación debido a las barreras del idioma; } \\
\text { festivales, eventos especiales; accesibilidad; } \\
\text { compras; actitud hacia los turistas; disponibi- } \\
\text { lidad / calidad de transporte local; los niveles } \\
\text { de precios. }\end{array}$ \\
\hline
\end{tabular}




\begin{tabular}{|r|l|l|}
\hline \multicolumn{1}{|c|}{ Autores } & \multicolumn{1}{|c|}{ Objetivo de Investigación } & \multicolumn{1}{|c|}{ Atributos del destino turístico } \\
\hline Kim (1998) & $\begin{array}{l}\text { Explorar la percepción de los } \\
\text { turistas para un destino }\end{array}$ & $\begin{array}{l}\text { Atractivo estacional y cultural; limpieza y } \\
\text { tranquilidad ambiental; calidad de los aloja- } \\
\text { mientos e instalaciones de ocio: comodidades } \\
\text { y seguridad orientados a la familia; la acce- } \\
\text { sibilidad y la reputación; oportunidades de } \\
\text { entretenimiento y recreativas }\end{array}$ \\
\hline $\begin{array}{r}\text { Lai y Graefe } \\
\text { (2000) }\end{array}$ & $\begin{array}{l}\text { Explorar la percepción de los } \\
\text { turistas para un destino }\end{array}$ & $\begin{array}{l}\text { Personal acogedor / servicios buenos y rá- } \\
\text { pidos; seguridad / protección; bajo coste / } \\
\text { gastos (comida barata / alojamiento / otras } \\
\text { instalaciones); ubicación / accesibilidad / dis- } \\
\text { tancia de proximidad; compra de arte / arte- } \\
\text { sanía / negocio; recomendación de amigos / } \\
\text { conocidos. }\end{array}$ \\
\hline Awaritefe (2004) & $\begin{array}{l}\text { Explorar la percepción de los } \\
\text { turistas para un destino }\end{array}$ & $\begin{array}{l}\text { Instalaciones / seguridad; lugares de interés; } \\
\text { accesibilidad práctica; calidad; accesibilidad } \\
\text { simbólica }\end{array}$ \\
\hline Formica y Uysal \\
(2006) & $\begin{array}{l}\text { Investigar los recursos y los } \\
\text { lugares de interés del destino } \\
\text { que atraen a los turistas; explo- } \\
\text { rar la percepción de los turistas } \\
\text { para un destino }\end{array}$ & $\begin{array}{l}\text { Servicios e instalaciones turísticas; culturales } \\
\text { aire libricos; alojamiento rural; recreación al }\end{array}$ \\
\hline
\end{tabular}

Fuente: Lee, Huang, y Chen (2010).

En suma, es posible afirmar que en la revisión de la literatura sobre elección del destino destacan como atributos del destino turístico: la cultura, el entorno natural y las instalaciones.

Para el caso concreto de destinos de luna de miel aún existe poca investigación. La percepción y la preferencia del destino turístico de los recién casados varía mucho en función de los distintos países (Lee, Huang y Chen, 2010). Japan Travel Bureau's (JTB, 2008) indica que los tres destinos de luna de miel más popular para los japoneses son Europa, Hawai y Okinawa. MacNair Travel \& Cruises (2006) en su encuesta para los recién casados de EEUU revela que Hawai, Tahití/Bora Bora e Italia son los tres mejores destinos de ensueño de luna de miel, y la playa y la cena son las dos principales actividades que buscan los recién casados. Turismo Australia revela que para los coreanos, los destinos preferidos son Australia, Maldivas y Guam (Dela Rosa Yoon, 2006). En el caso de España, según la agencia de viajes Smile Travel en Valencia (2014), Islas Griegas, Thailandia, Polinesia francesa y Seychelles son los destinos de viaje en pareja más demandados. Viajes Multidestino (2014) apunta que Asia volverá a ser el destino favorito de las parejas para vivir su luna de miel. Los recién casados chinos, qué analizaremos con más detalle en el siguiente punto, prefieren destinos asiáticos, Maldivas, Fiji, Malasia y Tailandia. Pero también europeos, destacando Grecia, Italia, Francia y Turquía (European Travel Commission y World Tourism Organitation, 2012). 
Además de la diversidad de la preferencia, el gusto de los recién casados también cambia. En caso de Latinoamérica, durante mucho tiempo las parejas latinoamericanas solían viajar en su luna de miel a Europa y Estados Unidos. En general, Italia, Francia, Grecia y las Islas del Mediterráneo fueron los destinos clásicos; y cuando llegaron los años 90, la zona del Caribe se convirtió en el lugar que más atraía a las parejas (Squillaro, 1997). Actualmente, El Caribe, Nueva York y ahora algunos países asiáticos, como Tailandia, son los destinos preferidos por las parejas uruguayas (Larronda, 2014).

Se detecta un vacío en la literatura en cuanto a atributos que determinan el atractivo de un destino de luna de miel se refiere. Lee, Huang, y Chen (2010) identifican cómo atributos más determinantes: la seguridad, la calidad excelente del alojamiento y el coste razonable del viaje.

Por su parte, Winchester, Winchester y Alvey (2011) coinciden en la importancia del presupuesto e incluyen la familiaridad y el romanticismo. Asimismo, destacan que el clima es un atributo más importante aquí que para otro tipo de turismo.

Del mismo modo, Kim y Agrusa (2005) incluyen entre atributos determinantes para un destino de luna de miel, el clima, la seguridad, el romanticismo, el presupuesto adecuado, y añaden otros como la comodidad, el paisaje, los recursos culturales/históricos y los lugares para ir de compras.

Lazzari, et al. (2009) realizan una investigación empírica de los atributos tenidos en cuenta por parte del segmento de 'jóvenes' para considerar un destino turístico. La muestra son 2520 individuos seleccionados de entre 18 y 29 años de las universidades argentinas. Aunque el segmento objetivo es diferente al segmento objetivo de la presente investigación resulta interesante ya que, como se ha mencionado previamente, los turistas de luna de miel son principalmente jóvenes (de edades comprendidas entre 25 y 35 años los hombres, y de entre 22 y 32 años, las mujeres). El resultado se muestra en la Tabla 6.

Tabla 6

LOS ATRIBUTOS DE ELECCIÓN DEL DESTINO Y NIVEL DE IMPORTANCIA PARA EL SEGMENTO DE TURISTAS JÓVENES

\begin{tabular}{|l|l|}
\hline NIVEL DE IMPORTANCIA & ATRIBUTOS \\
\hline Muy alta & Geografía del lugar; diversión; aventura; clima \\
\hline Alta & Factor humano; vida nocturna \\
\hline Media & Precio; infraestructura \\
\hline Baja-media & Actividades culturales; distancia \\
\hline Baja & Seguridad; medios de transporte \\
\hline
\end{tabular}

Fuente: elaboración propia a partir de Lazzari, et al. (2009).

Un reciente estudio analiza los factores objetivos y subjetivos para la elección de un destino internacional por parte de los turistas chinos (Wei, Meng y Zhang, 2017). Los resultados muestran que características demográficas, como la edad y el nivel de formación, y factores limitadores, como el tiempo para poder disfrutar de las vacaciones y el 
dinero o ingresos disponibles, influyen significativamente en la elección del destino de los ciudadanos chinos. En comparación con otros destinos, Europa y Estados Unidos son los más atractivos para los jóvenes, con mayor nivel educativo, con mayores ingresos y más tiempo de ocio para poder disfrutar de las vacaciones.

\section{TURISTAS CHINOS EN EL MERCADO INTERNACIONAL}

En este punto se analizan las características de los turistas chinos en el turismo internacional en general con el fin de investigar a este grupo de turistas en el turismo específico de luna de miel.

China sigue liderando el turismo emisor mundial, después de registrar año tras año desde 2004 tasas de crecimiento de dos dígitos en su gasto turístico. El gasto de los viajeros chinos creció un $26 \%$ en 2015 hasta alcanzar los 292.000 millones de dólares de los EE.UU., mientras que el total de viajeros creció un $10 \%$ hasta situarse en los 128 millones (OMT, 2016 p. 13) $)^{1}$. Se espera que la expansión de China se mantenga estable (+6,5\% en 2017), apoyada por la fuerte política, y que China siga liderando los viajes globales de salida debido al mayor poder adquisitivo de las clases medias, el aumento de la conectividad aérea y los viajes más asequibles (UNWTO, 2017).

Sin embargo, el mercado emisor chino para el turismo español es muy reducido, apenas supone un 0,49\% del total de turistas que llegaron a España en 2016 según país de residencia. De hecho, éste ha sufrido una disminución del 11,25\% en 2016 respecto al año anterior, según las estadísticas del INE (2017), con 374.295 turistas chinos en España (apenas un 0,29\% del total de turistas chinos). Por lo tanto, es importante conocer a los turistas chinos si España quiere aprovecharse de las ventajas de acoger a este nuevo mercado.

La Federación de las ciudades turísticas del Mundo (WTCF) junto con Ipsos llevan a cabo desde 2014 estudios de mercado anuales sobre el consumo de viaje de los turistas chinos en el mercado internacional. La investigación se va ampliando pero se mantiene la continuidad de los contenidos. En 2016 se obtuvieron 11.173 cuestionarios válidos. Según los informes de WTCF (2014, 2015 y 2016), las características de los turistas chinos en el mercado internacional que pueden ser interesantes para el presente estudio se muestran en la Tabla 7.

Diferentes estudios (Andreu, Claver y Quer, 2013; Andreu, Claver y Quer, 2014; Chen, Guevara y Alarcón, 2016; Lojo, 2016; Lojo y Cànoves, 2015; Tomás, 2011; UNWTO/ GTERC, 2016) muestran las características comunes de los turistas chinos en el mercado internacional. Los consumidores chinos son urbanitas, están hiperconectados y proyectan su estatus a través del gasto en viajes, convirtiéndose en una forma de expresión personal (UNWTO/GTERC, 2016). Viajes de larga distancia, con una duración media de 9 días, organizados por agencias de viajes, con elevado presupuesto y preferencia por las compras. Asimismo, Tomás (2011) apunta que los turistas chinos viajan atraídos por la cultura, el clima y las nuevas experiencias.

1 Nota: Debido a cambios de metodología, China revisó considerablemente al alza sus datos de gasto en turismo internacional para 2015 y retroactivamente para 2014 (OMT, 2016). 
Tabla 7

LOS TURISTAS CHINOS EN EL MERCADO INTERNACIONAL

\begin{tabular}{|c|c|}
\hline Aspecto & Conclusión \\
\hline Demografía & $\begin{aligned} \text { - Más de la mitad de los turistas chinos en el mercado internacional } \\
\text { nacieron durante los años } 80 \text {. } \\
\text { - El viaje en familia con los hijos menores de edad destaca en el } \\
\text { turismo emisor chino. } \\
\text { - El ingreso mensual promedio del individuo es de } 11.512 \text { yuan } \\
\text { (1.645 euros con tipo de cambio de } 7) \\
\text { - El promedio ingreso mensual de la familia es de } 20.767 \text { yuan } \\
\text { (2.966 euros con tipo de cambio de } 7)\end{aligned}$ \\
\hline Comportamiento & $\begin{array}{l}\text { - Más del } 70 \% \text { de turistas chinos viajan al extranjero al menos una } \\
\text { vez al año. De media, cada uno viajó al extranjero } 4,87 \text { veces, } \\
\text { visitando de } 3 \text { a } 4 \text { ciudades en } 2016 \text {. } \\
\text { - Más del } 90 \% \text { de los turistas chinos contratan seguros de } \\
\text { accidentes. } \\
\text { - El } 87,54 \% \text { de los turistas chinos eligen agencias de viajes para } \\
\text { organizar su viaje en el extranjero. } \\
\text { - Antes del viaje se informan y después comparten sus experiencias } \\
\text { en WeChat Moments o microblogs (el } 74,64 \% \text { y } 87,05 \% \text { ). } \\
\text { - No incluida la duración del desplazamiento al destino, la estancia } \\
\text { del viaje de la mayoría de los turistas chinos es de } 6-8 \text { días o 3-5 } \\
\text { días. } \\
\text { - El gasto total per cápita es de unos } 19.871 \text { yuan ( } 2838 \text { euros con } \\
\text { tipo de cambio de } 7 \text { ) } \\
\text { - Los turistas chinos ( } 57.76 \% \text { gastan un porcentaje elevado de su } \\
\text { presupuesto en ir de compras. }\end{array}$ \\
\hline $\begin{array}{r}\text { Los factores } \\
\text { atractivos }\end{array}$ & $\begin{array}{l}\text { Paisaje hermoso (73.56\%); Cultura singular }(68.64 \%) \text {; Historia } \\
(53.06 \%) \text {; Comida deliciosa }(48.49 \%) \text {; Buen clima y medio am- } \\
\text { biente }(48.26 \%) \text {; Edificios emblemáticos }(40.09 \%) \text {; Precio racional } \\
(33.34 \%) \text {; Bienes buenos y baratos }(29.09 \%) \text {; Abundantes museos } \\
(22.05 \%) \text {; Gente amable }(17.07 \%)\end{array}$ \\
\hline
\end{tabular}

Fuente: elaboración propia a partir de WTCF (2014, 2015 y 2016).

European Travel Commission y World Tourism Organization (2012) hace un estudio del mercado emisor chino utilizando una base de datos de 50 millones de microblogs y 20 millones de blogs de 2010 y 2011, con la forma de 'Netnography' -la rama de la etnografía que analiza el comportamiento espontáneo de los individuos en Internet, que utiliza las técnicas de investigación de marketing en línea para proporcionar información útil (Kozinets, 2009)-. Los resultados del análisis ayudan a comprender mejor el comportamiento de los turistas chinos en Europa (Véase Tabla 8). 


\section{Tabla 8 \\ LOS TURISTAS CHINOS EN EUROPA}

\begin{tabular}{|c|c|}
\hline ASPECTO & OPINIONES \\
\hline $\begin{array}{l}\text { Viajar en la } \\
\text { mente del } \\
\text { consumidor } \\
\text { chino }\end{array}$ & $\begin{array}{l}\text {-Viajar es la forma en la que los trabajadores de cuello blanco en las grandes ciudades escapan de la presión del trabajo. } \\
\text {-Los turistas chinos optan cada vez más por pasar menos tiempo desplazándose y más tiempo disfrutando. } \\
\text {-Las tiendas de lujo europeas se adaptando a los turistas chinos. } \\
\text {-Los turistas chinos intentan ahorrar dinero en comida, alojamiento y transporte, demandan los lugares de interés gratuitos. } \\
\text {-Los chinos que viven en ciudades de menor desarrollo se interesan cada vez más por Europa. } \\
\text {-El viaje de luna de miel se ha convertido en un símbolo de estatus. } \\
\text {-Los viajeros chinos traen sus dispositivos móviles en sus viajes a Europa. } \\
\text {-Los mochileros y otros grupos relativamente pequeños de viajeros popularizan destinos poco frecuentes de Europa a través } \\
\text { de Internet. } \\
\text { (European Travel Commission y World Tourism Organization, 2012:5) }\end{array}$ \\
\hline $\begin{array}{l}\text { El factor } \\
\text { tiempo }\end{array}$ & $\begin{array}{l}\text { El tiempo es un recurso escaso para la mayoría de los viajeros chinos y es una consideración importante en el proceso de } \\
\text { planificación. Las agencias de viajes tienden a satisfacer el deseo de los viajeros para maximizar el número de destinos } \\
\text { visitados durante un viaje. Otra forma de viajar de manera eficiente es visitar una ciudad representativa dentro de cada país. } \\
\text { (European Travel Commission y World Tourism Organization, 2012:21) }\end{array}$ \\
\hline Europa & $\begin{array}{l}\text {-Los turistas chinos en Europa buscan autenticidad, pero también quieren lo que están acostumbrados a tener en casa. } \\
\text {-Los chinos consideran que Europa es un lugar seguro. } \\
\text {-El papel de las artes y la cultura influyen en la decisión del viaje de los chinos. } \\
\text { (European Travel Commission y World Tourism Organization, 2012:24) } \\
\text {-La barrera del idioma es el obstáculo principal para los viajeros chinos independientes en Europa. } \\
\text { (European Travel Commission y World Tourism Organization, 2012:26) }\end{array}$ \\
\hline $\begin{array}{l}\text { Aspectos posi- } \\
\text { tivos de viajar } \\
\text { por Europa }\end{array}$ & $\begin{array}{l}\text { Las ciudades son tranquilas y limpias y el cielo azul. No están masificadas. Buena preservación de lugares de interés histó- } \\
\text { ricos. Protección del medio ambiente, medio ambiente limpio y hermoso. Cultura rica, alto nivel de sofisticación cultural. } \\
\text { Gente amable y servicial. Buen transporte público. Autobuses puntuales. Sistema de tren avanzado. Alimentos deliciosos y } \\
\text { seguros. Buena red de carreteras. } \\
\text { (European Travel Commission y World Tourism Organization, 2012:27) }\end{array}$ \\
\hline $\begin{array}{l}\text { Aspectos } \\
\text { negativos de } \\
\text { viajar por } \\
\text { Europa }\end{array}$ & $\begin{array}{l}\text { Las tarjetas de débito chinas no se pueden utilizar. Altos precios. Proceso tedioso de solicitud del visado. La falta de infor- } \\
\text { mación y materiales en idioma chino. Mala comida en general y mala comida china en particular. Necesidad de pagar por } \\
\text { utilizar los aseos. Diferentes monedas. Falta de transporte público en algunos destinos. Las tiendas cierran temprano. Mal } \\
\text { servicio. Baja eficiencia en el trabajo y falta de personal.Peor servicio e instalaciones en los hoteles europeos que en los de } \\
\text { China. Autopistas caras en algunos países. Costumbres groseras y rígidas. Grafitis en las ciudades. Pocas personas y vida } \\
\text { aburrida en la calle. Conducción caótica en algunas ciudades. Algunas ciudades no son todo lo limpias y ordenadas que } \\
\text { cabria esperar. Largas colas en las atracciones turísticas. Ladrones y falta de seguridad en algunas ciudades. } \\
\text { (European Travel Commission y World Tourism Organization, 2012:28) }\end{array}$ \\
\hline Luna de miel & $\begin{array}{l}\text {-El ir de luna de miel se ha convertido en un símbolo de estatus. Muchas parejas chinas que se casaron en los años } \\
\text { comprendidos entre } 1990 \text { y } 2000 \text { no tuvieron la oportunidad de ir de luna de miel y ahora, quieren hacerla. } \\
\text {-Los destinos populares incluyen los destinos domésticos como Lijiang y Xiamen y destinos asiáticos como Las Maldivas, Fiji, } \\
\text { Malasia y Tailandia. Europa también tiene altas puntuaciones en la lista, con Grecia, Italia, Francia y Turquía en la parte superior. } \\
\text {-La fotografía es un aspecto central de los viajes de luna de miel. Las parejas chinas invierten enormes cantidades de dinero } \\
\text { en la creación y captura de recuerdos. Están surgiendo grupos de viaje en torno al tema de la fotografía de bodas. } \\
\text {-La descripción del viaje de luna de miel utiliza palabras como "dulce", "feliz", "romántico" y "memorable". } \\
\text {-La creación de un entorno y de servicios para la captura de los recuerdos puede ser el desafío central para que los destinos } \\
\text { traten de atraer a los viajeros de luna de miel. } \\
\text { (European Travel Commission y World Tourism Organization, 2012:13-14) }\end{array}$ \\
\hline
\end{tabular}

Fuente: Traducción propia de European Travel Commission y World Tourism Organization (2012).

Cuadernos de Turismo, 40, (2017), 65-92 
La Administración Nacional del Turismo de China (CNTAIC, 2016), lista los 20 principales destinos internacionales del turismo chino en diciembre 2015 (último dato disponible), como muestra el Gráfico 5 (datos en diez mil visitas). Se ve que Asia sigue siendo el destino principal de los viajes internacionales. Estados Unidos ocupa la cuarta posición de los destinos (sin contar Hong Kong, Macao y Taiwán). Como destinos europeos destacan Rusia, Alemania, Reino Unido y Francia en las posiciones inferiores.

\section{Gráfico 5 \\ LOS 25 PRINCIPALES DESTINOS INTERNACIONALES DEL TURISMO CHINO EN DICIEMBRE 2015}

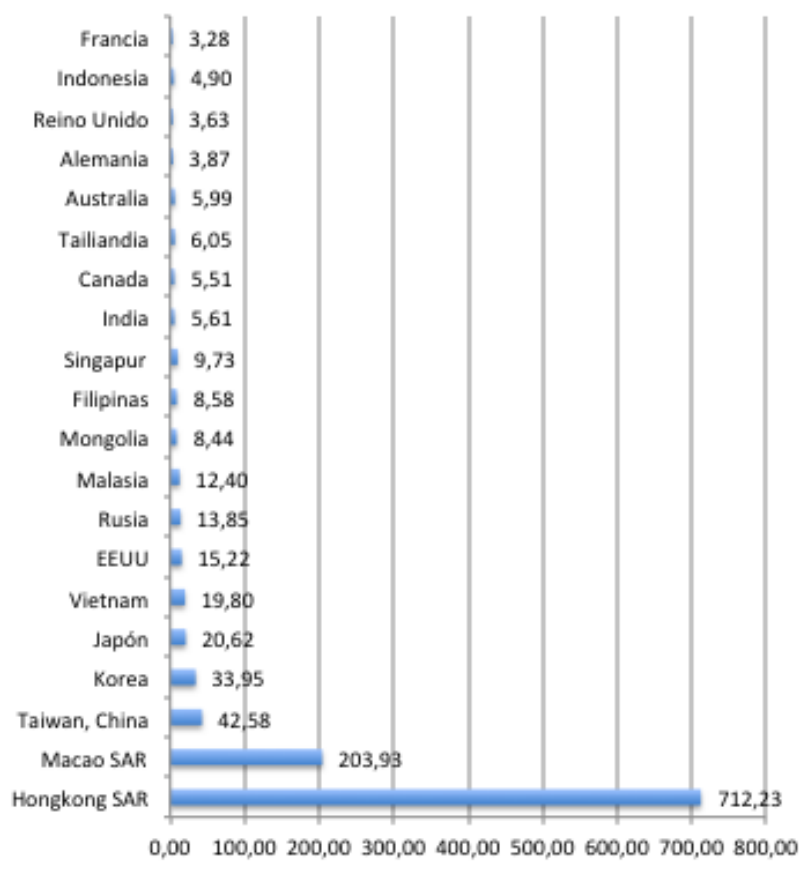

Fuente: CNTAIC (2016).

\section{CONCLUSIONES}

Esta demostrada la relevancia que han tomado los diferentes tipos de turismo alternativo en la actualidad, pero es prácticamente nula la investigación académica de algunos turismos específicos, como es el caso del turismo de luna de miel. A pesar de ello las empresas y administraciones turísticas empiezan a mostrar interés por este tipo de turismo y por atraer a los recién casados a sus destinos. Estas evidencias nos llevan a plantear dos cuestiones a investigar: (i) ¿Cuáles son las características del turismo de luna de miel en un marco de turismo alternativo? y (ii) ¿cuáles son los principales atributos del destino de luna de miel? 
Ahondando más en el turismo de luna de miel, el presente estudio se centra en el caso del segmento de turistas chinos por tres razones principales: son los que más están creciendo, para ellos es un boom la honeymoon, España está interesada. Lo que nos conduce a la tercera cuestión a investigar: (iii) ¿Cómo es el turista chino en el turismo internacional y europeo?

En primer lugar, se concluye que el turismo de luna de miel es un tipo de turismo alternativo específico en el que las parejas planifican con mucha antelación y deciden juntos un viaje de larga distancia y duración que realizan después de la boda para celebrar su matrimonio y pasar un tiempo romántico e íntimo. Durante el viaje, las parejas tienen una demanda específica y una actitud más exigente hacia los servicios, aceptando un precio relativamente alto.

En segundo lugar, el presente trabajo estudia el proceso de la elección del destino turístico, los atributos del destino que lo hacen más atractivo, y las pocas investigaciones sobre destino de luna de miel. Se concluye en este punto que la percepción y la preferencia del destino turístico de los recién casados varía mucho en los distintos países y el gusto de los recién casados cambia. Los atributos determinantes para un destino de luna de miel son: la comodidad, el paisaje, la seguridad, el romanticismo, el presupuesto adecuado, el clima, los recursos culturales/histórico, y los lugares para ir de compras (Kim y Agrusa, 2005).

Por último, el presente trabajo estudia los turistas chinos en el turismo internacional, sus perfiles, sus destinos preferidos, y cómo ellos piensan y se comportan en el viaje internacional. Los resultados muestran que el viaje de luna de miel de los chinos tienen sus propias peculiaridades. Por ejemplo, además de los jóvenes, las parejas chinas que se casaron entre los años 1990 y 2000 también quieren realizar un viaje de luna de miel; esto se ha convertido en un símbolo de estatus; crear y capturar recuerdos es la necesidad particular de los chinos en el turismo de luna de miel.

Llegados a este punto cabe decir que los resultados obtenidos en esta investigación son un primer paso para sentar las bases de este tipo de turismo para este tipo de turistas. De modo que las empresas o las ciudades mejoren la competitividad aprovechando este sector emergente. La investigación realizada no está exenta de limitaciones, derivadas de la escasez de fuentes bibliográficas existentes y de la desactualización de algunos de los datos estadísticos contemplados, pero las mismas suponen una importante línea de investigación futura que merece ser desarrollada. De ahí que las implicaciones prácticas de la investigación suponen la aplicación de los resultados teóricos en un estudio empírico a través de encuestas dirigidas al turista chino de luna de miel.

\section{BIBLIOGRAFÍA}

ABC.ES, (2014): «Los hoteles solo para adultos, opción de relax en auge en España y en el mundo». ABC Viajar. [en línea] Disponible en: http://www.abc.es/viajar/alojamientos/20140818/abci-hoteles-adultos-201408181215.html [Acceso 26 Enero 2017].

ALBACETE SÁEZ, C.A. y FUENTES, M.M. (2010): «Difusión de la investigación española sobre turismo en revistas internacionales», Revista de Análisis Turístico, 9, pp. 14-29. 
ALBADALEJO, P. y DÍAZ, M. (2003): «Rural tourism demand by type of accommodation», Tourism Management, vol. 26, pp. 951-959.

ANDREU, R., CLAVER, E. y QUER, D. (2013): Chinese Outbound Tourism: New Challanges for European Tourism, [en línea] Disponible en: http://www.uhu .es/publicaciones/ojs/index.php/et/article/view/2097

ANDREU, R. CLAVER, E. y QUER, D. (2014): «Destination Attributes and Chinese Outbound Tourism to Europe». Journal of China Tourism Research, vol. 10, nº 3, pp. 275-291.

ARAGONÉS-JERICÓ, C. (2013): La transferencia entre un gran evento deportivo y la marca patrocinadora: la visión del visitante deportivo. Tesis Doctoral. Universidad de Valencia. Disponible en: http://roderic.uv.es/handle/10550/28901

ARMADANS, I. (1999): «Tendències dels Turistes a les Portes del 2000. ETC». Estudis de Turisme de Catalunya, 4, pp. 18-23.

BACCI, M.E. (2007) «La Importancia de la Gestión en el Turismo Urbano» Fórum Cultura. Universal de las Culturas 2007. Encuentro Internacional de Turismo Urbano y Septiembre 2007. Monterrey, México.

BENCKENDORFF, P., (2009): «Themes and trends in Australian and New Zealand tourism research: A social network analysis of citations in two leading journals (19942007)», Journal of Hospitality and Tourism Management, vol. 16, pp. 1-15.

BOUCHET, P., LEBRUN, A. M. y AUVERGNE, S. (2004): «Sport tourism consumer experiences: a comprehensive model». Journal of Sport \& Tourism, vol. 9(2), pp. 127-140.

BUENO, J.C.C., MENÉNDEZ, A.M.M., y GARCÍA, M.D. L.Á.O. (1995): «El turismo alternativo como un sistema integrado: consideraciones sobre el caso andaluz». Estudios turísticos, $\mathrm{n}^{\circ} 125$, pp. 53-74.

CANARIASDIARIO.COM, (2014): «Canarias presenta su plataforma de turismo de Bodas» (18 Octubre 2014). Canarias Diario. [en línea] Disponible en: http://www. canariasdiario.com/canarias-presenta-su-plataforma-de-turismo-de-bodas [Acceso 26 Enero 2017].

CASTRO, R. Q. (2006): Elementos del turismo. EUNED.

CAZES, G.H. (1989): «Alternative tourism. Reflections on an ambiguos concept». En: Singh, T.V., Theuns, H.L., Go, F.M.: Towards Appropriate Tourism: The Case of Developing Countries, Frankfurt, P Lang.

COHEN, E. (1989): «Alternative tourism. A critique». En: Singh, T. V., Theuns, H. L., Go, F. M.: Towards Appropriate Tourism: The Case of Developing Countries, Frankfurt, P. Lang.

COOPER, C. y HALL, C.M. (2008): Contemporary Tourism: An International Approach, Edit. Butterworth-Heinemann

CHEN, F.-W., GUEVARA, A. y ALARCÓN, P. (2016): «Automatically extracting tourism-related opinion from Chinese social media». Current Issues in Tourism, vol. 20(10), pp. 1-18.

CHINA NATIONAL TOURISM ADMINISTRATION (CNTAIC) (2016): Major Source Markets in December 2015 [en línea] Disponible en: http://en.cnta.gov.cn/Statistics/ TourismStatistics/index.shtml [Acceso 26 Enero 2017]. 
DANN, G.M.S. (1977): «Anomie, Ego-Enhancement and Tourism». Annals of Tourism Research, vol.4 (4), pp. 184-194.

DELA ROSA YOON, R. (2006): «Australia tops latest poll as honeymoon spot for Koreans». The Seoul Times. [en línea] Disponible en: http://theseoultimes.com/ $\mathrm{ST} /$ ?url=/ST/db/read.php?idx=4611 [Acceso 26 Enero 2017].

DIARIOSUR.ES (2014): «Málaga se comercializa como destino de luna de miel de las parejas chinas» (1 Julio 2014). Diario Sur. [en línea] Disponible en: http://www. diariosur.es/turismo/201407/01/malaga-comercializa-como-destino-20140701163402. html [Acceso 26 Enero 2017].

DÍAZ-CARRIÓN, I.A. (2013): «Mujeres y mercado de trabajo del turismo alternativo en Veracruz». Economía, sociedad y territorio, 13(42), pp. 351-380.

EUROPEAN TRAVEL COMMISSION AND WORLD TOURISM ORGANIZATION, (2012), Understanding Chinese Outbound Tourism - What the Chinese Blogosphere is saying about Europe. UNWTO, Madrid.

FORMICA, S. y UYSAL, M. (2006): «Destination attractiveness based on supply and demand evaluations: An analytic framework». Journal of Travel Research, vol. 44(4), pp. 418-430.

FULLANA, P., I PALMER, P.F. y AYUSO, S. (2002): Turisme sostenible. Departament de Medi Ambient.

GARCÍA A. y ARTAL, A. (2002): «El turismo de segunda residencia-El Mar Menor», Revista da Escola Superior de Gestao Hotelaria e Turismo, Dos Algarves, Universidade do Algarbe, vol.10, pp. 12-16.

GARCÍA T. (2014). «Mil y un destinos para perderse». (13 Julio 2014). Levante-El Mercantil Valenciano. [en línea] Disponible en: http://www.levante-emv.com/sociedad/2014/07/13/mil-destinos-perderse/1137280.html [Acceso 26 Enero 2017].

GARCÍA, A.; ARTAL, A. y RAMOS, J.M. (2002a): «El turismo del Mar Menor: predominio de la segunda residencia», Cuadernos de Turismo, no 9, pp. 33-43.

GARCÍA, A.; ARTAL, A. y RAMOS, J.M. (2002b): Análisis del turismo en el Mar Menor durante 2001, Departamento de Economía de la Universidad Politécnica de Cartagena (UPCT).

GARD MCGEHEE, N. (2002): «Alternative tourism and social movements» Annals of Tourism Research, vol. 29 (1), pp. 124-143.

GEARING, C., SWART, W. y VAR, T. (1974). «Establishing a measure of touristic attractiveness». Journal of Travel Research, vol. 12(4), pp. 1-8.

GETZ, D. (2005): Event Management \& Event Tourism. Cognizant Communication Corporation.

GETZ, D. (2008): «Event tourism: Definition, evolution, and research». Tourism Management, vol. 29, pp. 403-428.

GOELDNER, C.R., y RITCHIE, J.B. (2006): Tourism: Principles, practices, philosophies. John Wiley \& Sons.

GONZALEZ, E. (2015): «Spain takes pains to lure more tourists from China». (14 Septiembre 2015). China Daily. [en línea] Disponible en: http://usa.chinadaily.com.cn/ epaper/2015-03/24/content_19895108.htm [Acceso 26 Enero 2017]. 
HU, Y. y RITCHIE, J.B. (1993): «Measuring destination attractiveness: a contextual approach». Journal of Travel Research, 32(2): pp. 25-34.

INSTITUTO NACIONAL DE ESTADÍSTICA (INE) (2017): Movimientos turísticos en fronteras. Diciembre 2016.(publicado 1 Enero 2017) Madrid. INE.

IVARS, J., RODRÍGUEZ, I. y VERA, J.F. (2013): «The evolution of mass tourism destinations: new approaches beyond deterministic models in Benidorm (Spain)». Tourism Management, vo. 34, pp. 184-195.

JANG, H., LEE, S., LEE, S. W. y HONG, S.K. (2007): «Expanding the individual choicesets model to couples' honeymoon destination selection process». Tourism Management, 28(5), pp. 1299-1314.

JAPAN TRAVEL BUREAU (JTB) (2008): «JTB Survey of Wedding \& Honeymoon Intentions ». (17 Octubre 2008) [en línea] Disponible en: http://www.jtbcorp.jp/en/ press_release/ [Acceso 26 Enero 2017].

KIM, H-B. (1998): «Perceived Attractiveness of Korean Destinations». Annals of Tourism Research, Vol.25 (2), pp. 340-361.

KIM, S.S. y AGRUSA, J. (2005): «The positioning of overseas honeymoon destinations». Annals of Tourism Research, 32(4), pp. 887-904.

KIM, S. S. y AGRUSA, J. (2008): «Segmenting Japanese tourists to Hawaii according to tour purpose». Journal of Travel \& Tourism Marketing, 24(1), pp. 63-80.

KIRCHLER, E. (1993): «Spouses' joint purchase decisions: Determinants of influence tactics for muddling through the process». Journal of Economic Psychology, vol. 14(2), pp. 405-438.

KOZINETS V. y ROBERT (2009): Netnography: Doing Ethnographic Research Online, Sage Publications.

LARRONDA, A. (2014): «La agencias de viajes seducen a los mieleros con sus colectivos de bodas". (11 Julio 2014). El País. [en línea] Disponible en: http://www.elpais.com. uy/el-empresario/agencias-viajes-seducen-mieleros-colectivos.html [Acceso 26 Enero 2017].

LAW, E. (1995): Tourist resort management, issues, analysis and policies.

LAZZARI, L.L. (2006): El comportamiento del consumidor desde una perspectiva fuzzy. Tesis Doctoral. Universidad de Valladolid.

LAZZARI, L., MOULIÁ, P., FERNANDEZ, M.J., CHIODI, J., CHELMICKI, F., CHIODI, M. y ERIZ, M. (2012): «Preferencias del segmento joven en la elección de un destino turístico. Cuadernos del CIMBAGE, (11).

LEE, C. F., HUANG, H. I., y CHEN, W. C. (2010): «The determinants of honeymoon destination choice-The case of Taiwan". Journal of Travel \& Tourism Marketing, 27(7), 676-693.

LI, X. R. (Ed.). (2016): Chinese outbound tourism 2.0. Apple Academic Press.

LOJO, A. (2016): «Chinese tourism in Spain: An analysis of the tourism product, attractions and itineraries offered by Chinese travel agencies». Cuadernos de Turismo, $\mathrm{n}^{\circ}$ 37, pp. 243-268.

LOJO, A. y CÀNOVES, G. (2015): «El turismo chino en Barcelona. Elementos clave de un fenómeno reciente». Documents d'Anàlisi Geogràfica, vol. 61(3), pp. 581-599. 
LUCENA (2015): «Hay destinos muy atractivos para el viaje de luna de miel ». (21 Febrero 2014). Diario Córdoba [en línea] Disponible en: http://www.diariocordoba.com/noticias/ lucena/hay-destinos-atractivos-viaje-luna-miel_862142.html [Acceso 26 Enero 2017].

LUQUE, GIL, A.M. (2003): «La evaluación del medio para la práctica de actividades turístico-deportivas en la naturaleza». Cuadernos de Turismo, n 12, pp. 131-149.

MACNAIR TRAVEL \& CRUISES (2006). «Honeymoon trends survey reveals Hawaii is top dream honeymoon spot \& August is premier month for travel». Macnair. [en línea] Disponible en: http://www.macnairtravel.com/news_and_tools/archives [Acceso 26 Enero 2017].

MARCO, C.M. (2015): «El turista chino desprecia a España como destino turístico» (25 Febrero 2015). Cinco Días. [en línea] Disponible en: http://cincodias.com/cincodias/2015/02/25/emprendedores/1424875989_768086.html [Acceso 26 Enero 2017].

MCDONAL S.M., y MURPHY, P. (2008): «Utilizing and Adapting Leisure Constraints Models to Enhance 'Short-Break' Vacations. Case Study of Melbourne, Australia». Journal of Vacation Marketing, vol.4 (4), pp. 317-333.

MINISTERIO DE ENERGÍA, TURISMO Y AGENDA DIGITAL, (2010) Plan de turismo China [en línea] Disponible en: http://www.minetad.gob.es/es-es/gabineteprensa/notasprensa/documents/planturismochina.pdf [Acceso 26 Enero 2017].

MINISTERIO TRABAJO Y SEGURIDAD SOCIAL. Real Decreto Legislativo 1/1995, de 24 marzo de 1995. [en línea] Disponible en: https://www.boe.es/buscar/doc. php?id=BOE-A-1995-7730 [Acceso 26 Enero 2017].

MINMIN, D. (2015): «Handshake for Tourism Cooperation between China and Spain» (14 Septiembre 2015). 国家旅游局信息中心 [en línea] Disponible en: http://en.cnta. gov.cn/focus/travelnews/201507/t20150707_721377.shtml [Acceso 26 Enero 2017].

MONTEFORTE, M. (2008): Del saqueo a la conservación: Historia ambiental contemporánea de Baja California Sur, 1940-2003. Instituto Nacional de Ecología.

MOWFORTH, M. (1993): Eco-tourism: terminology and definitions. University of Plymouth, Department of Geographical Sciences.

ORGANIZACIÓN MUNDIAL DEL TURISMO (OMT) (2016): Panorama OMT del turismo internacional, edición 2016. Madrid, OMT.

OSORIO GARCÍA, M. (2010): «Turismo masivo y alternativo. Distinciones de la sociedad moderna/posmoderna». Convergencia, vol. 17, n 52, pp. 235-260.

PARK, C.W. (1982): «Joint decisions in home purchasing: A muddling-through process». Journal of Consumer Research, 151-162.

PARTIDO ANDALUCISTA, (2014): «La Secretaría de Turismo del PA lanza una campaña para promocionar Andalucía como destino de boda» (10 Octubre 2014). Malaka.es. [en línea] Disponible en: http://www.malaka.es/noticias_ampliar.php?id=44134\&com esfrom=columnista.php [Acceso 26 Enero 2017].

PULIDO, C.O. (2014): «Los españoles no renuncian al viaje de novios». (8 Mayo 2014). Cinco Días. [en línea] Disponible en: http://cincodias.com/cincodias/2014/05/08/sentidos/1399572981_190068.html [Acceso 26 Enero 2017].

QUANDL (2015): «Age at First Marriage - Female By Country ». [en línea] Disponible en: https://www.quandl.com/collections/demography/age-at-first-marriage-female-bycountry [Acceso 26 Enero 2017]. 
QUANDL (2015): «Age at First Marriage - Male By Country».[en línea] Disponible en: https://www.quandl.com/collections/demography/age-at-first-marriage-male-bycountry [Acceso 26 Enero 2017].

RUIZ, J., SÁNCHEZ, A. y ARTAL, A. (2003): El Turismo de Salud, Características y Potencialidades: Análisis Aplicado al Mar Menor. Trabajo de Investigación de Tercer Ciclo. Universidad Politécnica de Cartagena.

SANCHO, A. (2006): «Debate: Validez de las fuentes de información del turismo español», Revista de Análisis Turístico, nº1, pp. 57-58.

SPIRO, R. L. (1983). «Persuasion in family decision-making». Journal of Consumer Research, 393-402.

SQUILLARO, G. (1997): «Viajes y turismo: Inolvidable luna de miel en...puerto rico». (13 Febrero 1997). La Prensa. [en línea] Disponible en: https://search.proquest.com/ docview/368535292?accountid=14777 [Acceso 26 Enero 2017].

SQUILLARO, G. (2006): «Viajes y turismo; de luna de miel». (09 Febrero 2006). La Prensa. [en línea] Disponible en: https://search.proquest.com/docview/368739096?ac countid=14777 [Acceso 26 Enero 2017].

TOMÁS, D. (2011): El turismo chino en España: la adaptación de destinos turísticos españoles al mercado turístico más grande del mundo. Universidad de Sevilla. [en línea] Disponible en: http://www.fundacionico.es/fileadmin/user_upload/pdfs/ El_Turismo_Chino_en_Espana_2.pdf [Acceso 26 Enero 2017].

TROITIÑO VINUESA, M.A. (2002): «Turismo y recuperación urbana», en El turismo en Castilla-La Mancha. Análisis y perspectivas. Cuenca, Universidad de Castilla-La Mancha, pp. 29-43.

UM, S. y CROMPTON, J.L. (1990): «Attitude determinants in tourism destination choice». Annals of tourism research, vol. 17(3), pp. 432-448.

UNWTO (2017): World Tourism Barometer and Statistical Annex, Advance release January 2017. 15(1)

VALLANO, R. (2012): «Establecimientos Solo Adultos: Una especialización en crecimiento». Alimarket: Hoteles y Restauración: Hostelmarket, nº148, pp. 2-11.

VIZCAÍNO, M.L. (2016): «Nuevas potencias turísticas». International Journal of Scientific Managment Tourism, vol. 2 (2), pp. 491-513.

VODENSKA, M. (2013): «New Marketing Approaches and Emerging Tourism Products». International Journal of Management Cases, vol. 15(4), pp. 122-132.

WEI-NA, L.I. (2011): «A Review of the Choice Models of Overseas Classical Tourist Destinations [J]». Tourism Tribune, 5, 012.

WEI, X., MENG, F., y ZHANG, P. (2017): «Chinese Citizens' Outbound Destination Choice: Objective and Subjective Factors». International Journal of Tourism Research, 19(1), pp. 38-49.

WINCHESTER, M., WINCHESTER, T. y ALVEY, F. (2011): «Seeking romance and a once in a life-time experience: Considering attributes that attract honeymooners to destinations». En ANZMAC 2011 conference proceedings: Marketing in the Age of Consumerism: Jekyll or Hyde? (pp. 1-7). ANZMAC.

WORLD TOURISM CITIES FEDERATION (WTCF) (2014): Market research report on Chinese outbound tourist (city) consumption. [en línea] Disponible en: http://en.wtcf. org.cn/Research/WTCFReports/ [Acceso 26 Enero 2017]. 
WORLD TOURISM CITIES FEDERATION (WTCF) (2016): Market research report on Chinese outbound tourist (city) consumption (2015-2016). [en línea] Disponible en: http://en.wtcf.org.cn/Research/WTCFReports/ [Acceso 26 Enero 2017].

WORLD TOURISM ORGANIZATION AND GLOBAL TOURISM ECONOMY RESEARCH CENTRE (2016): UNWTO/GTERC Annual Report on Tourism Trends - 2016 Edition, UNWTO, Madrid. 